\title{
A NEW PHYSICAL SIGN IN SHOULDER ARTHROSCOPY
}

\author{
S. A. COPELAND, D. S. BARRETT
}

Arthroscopy is not as commonly performed at the shoulder as at the knee, but in both cases distension of the joint by injection of saline is used to facilitate insertion of the arthroscope. At the knee the prominence of bony landmarks makes injection a simple procedure. The shoulder is deeply situated and more difficult to palpate, so that inadvertent injection of saline into the soft tissues around the capsule is quite possible. Moreover, the error is not apparent at the shoulder as it is at the knee, and the accumulation of saline in the musculoligamentous complex causes collapse of the joint capsule. Introduction of the arthroscope is then difficult and the procedure may have to be abandoned until the interstitial fluid has dispersed.

We describe a sensitive and reliable clinical sign which, when positive, provides convincing evidence that the saline is inside the joint.

Method. The patient is prepared in the standard lateral decubitus position, with the affected shoulder uppermost and the forearm supported horizontally. Injection of saline and arthroscopy are performed through the posterior portal to the shoulder as described by Detrisac and Johnson (1986). The entry point is situated $1 \mathrm{~cm}$ medial and $1 \mathrm{~cm}$ caudal to the posterolateral corner of the acromion (Johnson 1980); $60 \mathrm{ml}$ of saline are injected. Providing the capsule has been distended successfully, the shoulder automatically abducts and rotates internally. The presence of free backflow followed by return to the neutral position confirm the correct placement of the needle. This movement occurs early in the distension process and thus failure to observe this sign allows repositioning of the needle and syringe before the injection of a significant amount of saline into the surrounding tissues renders arthroscopy difficult.

Discussion. The abduction-internal-rotation movement on distension of the joint is produced by filling of the normally lax postero-inferior segment of the capsule. Due

\footnotetext{
S. A. Copeland, FRCS, Consultant

D. S. Barrett, BSc, FRCS, Registrar

Orthopaedic Department, Royal Berkshire Hospital, London Road, Reading, Berkshire, England.

Correspondence to Mr D. S. Barrett at 76 Northcroft Road, West Ealing, London W13 9SX, England.

(C) 1989 British Editorial Society of Bone and Joint Surgery $0301-620 X / 89 / 5 \mathrm{R} 39 \$ 2.00$

J Bone Joint Surg [ Br] 1989:71-B:860.
}

to pressure differentials, this part of the capsule fills first and the initial movement is observed after only $20 \mathrm{ml}$ of fluid have been injected.

The presence of an effusion in large joints produces characteristic limitation of movement. The position adopted is a function of the capsular attachment to the joint margins and the direction of the ligamentous reinforcements of the capsule. Thus in the hip, due to the spiral arrangement of the capsular fibres the position of greatest relaxation and maximum potential volume of the joint is in the 'unwound' position of flexion and external rotation (Walmsley 1928). This position is thus associated with the minimum measured intra-articular pressure (Godard and Gosling 1988), reducing the stimulus to joint capsule mechanoreceptors and lessening capsular pain. The position of the shoulder in similar circumstances is directly analogous, being a function of the lax postero-inferior segment of the capsule and the spiral nature of the three glenohumeral ligaments. The abduction-internal-rotation position of the shoulder in the presence of an effusion has not, as far as we know, been previously reported.

The alternative method of judging the success of capsule distension is the ease with which saline may be introduced into the joint. Difficult injection of a small quantity of saline indicates that the needle tip is outside the joint. However, if it rests in one of the many tissue planes around the shoulder, injection of a large quantity of saline is possible with ease before the error is realised and the opportunity of arthroscopy may be lost.

We believe the clinical sign we have described is a reliable and early indicator of successful distension of the shoulder capsule. It has been used effectively by the senior author for over eight years and is now part of our routine in shoulder arthroscopy.

No benefits in any form have been received or will be received from a commercial party related directly or indirectly to the subject of this article.

\section{REFERENCES}

Detrisac DA, Johnson LL. Arthroscopic shoulder anatomy : pathology and surgical implications. New Jersey: Slack, 1986.

Godard NJ, Gosling PT. Intra-articular fluid pressure and pain in osteoarthritis of the hip. J Bone Joint Surg [Br] 1988;70-B:52-5.

Johnson LL. Arthroscopy of the shoulder. Orthop Clin North Am 1980:11:197-204,

Walmsley T. The articular mechanism of the diarthroses. $J$ Bone Joint Surg 1928;10:40-5. 